\title{
Creating Community: Latina Nannies in a West Los Angeles Park
}

\author{
Amada Armenta
}

Published online: 28 April 2009

C The Author(s) 2009. This article is published with open access at Springerlink.com

\begin{abstract}
Drawing on 1 year of ethnographic fieldwork in Los Angeles, this article examines how Latina nannies create workplace solidarity in a public park. This article reveals how nannies use public spaces in the neighborhoods in which they work to establish ties similar to co-worker relations in other settings. This paper demonstrates how nannies create a community at the park by incorporating park staff into their activities, reinforcing group values such as sharing and reciprocity, and distinguishing themselves from their employers. Adding to previous research which highlights the atomization and stigmatization that comes with domestic employment, this article shows how nannies create co-worker relationships that are buffers against unfavorable job conditions such as solitary work settings and unappreciative employers.
\end{abstract}

Keywords Latina/o immigrants $\cdot$ Domestic work $\cdot$ Labor

Every day in Los Angeles, affluent neighborhoods import Latino service workers such as gardeners, maids, and nannies to perform household tasks. The influx of workers increases social inequalities within households and neighborhoods, because employers are often of a different racial/ethnic group and socioeconomic status than those they employ. However, the same characteristics that distinguish household service workers from their employers serve as the foundation for their informal ties with one another. Neighborhood workers share similar low-wage labor positions, and often language and culture, creating the opportunity for Latino workers to create communities in non-Latino neighborhoods.

This paper extends and deepens this insight through a case study of nannies that regularly gather in a public park during their workdays. Although domestic work is often characterized as being socially isolating, this paper illustrates how the structure of domestic work enables women to create communities in their employers' neighborhood. As such, the

\footnotetext{
A. Armenta $(\bowtie)$

Department of Sociology, University of California, Los Angeles, 264 Haines Hall, 375 Portola Plaza, Los Angeles, CA 90095, USA

e-mail: armenta@ucla.edu
} 
public park that women attend during work becomes a site through which nannies expand their networks by meeting one another and other Latino workers.

\section{Social isolation}

Domestic work entails a variety of labor arrangements including "live-in" work, "live-out" work, and "job work." "Live-in" or "live-out" domestics can be employed as nannies and/or housekeepers, while women engaged in "job work" clean multiple households and are paid by the job (Hondagneu-Sotelo 2001; Romero 1992). Although the social organization of each type of domestic work varies, most research supports the claim that domestic workers, particularly live-in domestics, are socially isolated.

Researchers interested in employee well-being document that co-worker relationships improve individual job satisfaction by combating social isolation (Fantasia 1988; Goffee 1981). Of course, the degree to which workers can create a cohesive group depends on the circumstances in which they work. Job characteristics, workforce characteristics, and characteristics of the employing organization are important determinants of co-worker cohesion (Hodson et al. 1993).

Many characteristics of domestic employment make solidarity and community amongst workers a challenge. For example, the occupation's high employee turnover makes the workplace unstable (Hondagneu-Sotelo 2001). Workplaces with high turnover have less group solidarity because individuals do not have time to identify with one another (Littler and Salaman 1984). In addition, while shared work experiences are the foundation for maintaining co-worker relationships (Fantasia 1988; Goffee 1981), domestic workers do not share a common work site, limiting their opportunities for personal interactions with similarly employed women (Hagan 1998; Hondagneu-Sotelo 2001). The costs of this social isolation are not merely emotional. Hagan (1998) shows that because of domestics' limited social networks, they were not able to take advantage of amnesty provisions like their male counterparts with more extensive networks, and therefore could not legalize their status.

\section{Employer-employee relationships}

The majority of research on domestic labor documents the employment conditions women face on the job, particularly their relationships with employers (Clark-Lewis 1994; Hondagneu-Sotelo 2001; Lan 2003; Macdonald 1998; Palmer 1989; Parreñas 2001; Rollins 1985; Wrigley 1995). Domestic workers are often of a different race, class, and legal status than their employers, and their interactions reflect these social inequalities (Glenn 1986; Hondagneu-Sotelo 2001; Rollins 1985; Romero 1992; Palmer 1989; Wrigley 1995). For example, employers dictate the terms of domestic employment, including hours, duties, and work arrangements (Hondagneu-Sotelo 2001; Lan 2003; Rollins 1985; Romero 1988; Wrigley 1995).

Employers engage in boundary work to mark their different class and ethnic statuses than the women they employ (Lan 2003). Some employers expect domestic workers to express subservience or deference (Hondagneu-Sotelo 2001; Rollins 1985; Romero 1992; Wrigley 1995). Wrigley (1995) showed that employers expect minority nannies to work harder or complete more tasks than middle-class European au pairs. Domestic workers and their employers also do not have the same right to space in the household (Lan 2003). For 
example, employees eat alone because they feel they do not belong at the table with employers; moreover, certain areas of the home are deemed "off limits" for workers (Hondagneu-Sotelo 2001; Lan 2003, 2006; Rollins 1985). Afraid that employees will learn of better work opportunities if they spend time with other domestics, some employers deny women time off work, reinforcing feelings of social isolation (Hondagneu-Sotelo 2001; Lan 2006).

\section{Co-worker relationships}

Despite their social isolation, some scholars document domestic workers' relationships with one another, particularly as they occur in public space. Several scholars use Goffman's metaphor of the stage to describe how domestic workers behave when they are on and off work. According to Goffman (1959), people exhibit a different "presentation of self" depending on their audience; domestic workers behave differently with employers (on the front stage) than during time off work (on the back stage) (Cohen 1991; Lan 2003). Public places provide an important "backstage" function for domestic workers because they feel more private than the homes in which domestics work (Cohen 1991; Lan 2003; Yeoh and Huang 1998).

Parreñas (2001) describes groups of domestics as "pockets" of gathering because women congregate in public spaces around the city, but are still segregated from dominant society. On their days off, women create "weekend enclaves" replete with ethnic food, dancing, and joking (Lan 2006; Parreñas 2001). Some workers create "family-like" relationships with one another by sharing apartments on weekends and gossiping about employers together (Cohen 1991). Weekend gatherings become sites of social support where women share information about work and wages, thereby creating a collective work culture (Cohen 1991; Hondagneu-Sotelo 1994a; Lan 2006; Parreñas 2001). Through these interactions, women achieve a sense of social belonging and reclaim their autonomy (Lan 2006; Parreñas 2001).

While this literature illustrates how domestics establish relationships with one another during their time off work, weekend gatherings are often characterized as reactions to domestic work. For example, they are described as a way to "reclaim autonomy" or as “coping strategies" (Cohen 1991; Lan 2006; Parreñas 2001). In addition, despite the existence of networks between domestic workers, scholars do not question the degree to which domestic work is socially isolating. For example, even gatherings in public spaces are described as socially isolated (Parreñas 2001).

While most scholarship highlights the benefits of social networks between domestic workers, sometimes immigrant networks operate as "networks of exploitation" (Cranford 2005). Hondagneu-Sotelo's (1994a) work on social networks among Latina housecleaners shows that for some women social networks result in better working conditions while for others they depress wages. Thus, apprenticeship relationships between more and less experienced housecleaners allow inexperienced housecleaners to get their foot in the door, but they also lock them into poor paying jobs as helpers (Romero 1992; Hondagneu-Sotelo 1994a).

Unlike previous research, my paper focuses on the relationships domestic workers create with one another in their employers' neighborhood. Latina nannies in West Los Angeles spend time in the same public park because their employers encourage or request that they take their children there. Thus, I argue that the structure of domestic work 
provides opportunities for women to create community during the normal course of the workday.

\section{Data and methods}

This paper focuses on live-in and live-out nannies; although their work involves a myriad of simultaneous tasks like cooking or cleaning, their principle roles involve caring for their employers' children. Most studies of domestic labor tend to be historical (Dudden 1983; Glenn 1986; Katzman 1978; Palmer 1989) or interview based (Dill 1988; Glenn 1986; Hondagneu-Sotelo 2001; MacDonald 1998; Romero 1988, 1992; Wrigley 1995). With the exception of Rollins (1985) whose research is informed by her own work as a domestic, research that has relied on ethnographic observations focuses on what women do during their days off work (Cohen 1991; Hondagneu-Sotelo 1994a, b; Lan 2006; Parreñas 2001; Yeoh and Huang 1998). Instead, my work uses ethnographic observations to examine relationships between domestics when they are on the job and at work.

My research relies on a year of ethnographic observations between January and December of 2005 at "Pebble Park," a public park in an affluent West Los Angeles neighborhood. In 2000, households in the park's census tract had a median income of $\$ 135,487$ a year, compared to $\$ 41,994$ nationally; the median home value in the Pebble Park census tract was over $\$ 1,000,000$ compared to $\$ 119,600$ nationally (U.S. Census 2000). The park is large and accommodates many patrons including neighborhood laborers eating at an adjacent taco truck, golfers practicing on the putting green, and lawn bowlers perfecting their games. Several men, who work as park staff, drive by in golf carts to oversee park maintenance, and nannies, looking after children, sit on benches around the playground.

I went to Pebble Park about 4 times a week on weekdays, and after every trip to the field, I wrote my observations in detailed field notes (Emerson et al. 1995). I focused on a particular group of nannies that spent time together almost every weekday between the hours of 10:00 A.M. and 2:00 P.M. This group included up to 12 women, but only 8 were core members who attended the park several times a week and always spent time with one another. Of this core group, the youngest nanny was 23 and the oldest was 47 . Most of the nannies were foreign born-3 were Mexican, 6 were from El Salvador, and 2 were from Guatemala - the other nanny, Marlena, was a native-born Mexican-American. The majority of nannies in this group were live-out workers. The women chose domestic work because it offered more flexibility and higher pay than previous jobs or other jobs that were available. Nannies in this group earned between $\$ 250$ and $\$ 450$ a week. Two women also received insurance benefits and paid holidays.

I participated in the social life nannies created at the park and conducted field interviews through the course of regular interaction and conversation. After compiling a year of data, roughly 150 pages of notes, I coded the data for analytic themes (Katz 2001). All conversations occurred in Spanish and were translated into English for this paper, unless otherwise noted. I limited my interactions with nannies' employers because I did not want to jeopardize my relationship with nannies at the park. As a result, this paper reflects the nannies' points of view, rather than their employers. Like Parreñas (2001), I use the "subject approach" which acknowledges both structure and agency as it relates to domestic workers. Thus, this paper demonstrates the agency and power that domestic workers exercise while on the job, but it acknowledges that their subordinate positions restrict their autonomy. 


\section{Sources of community life}

\section{Working at the park}

Unlike other domestics, whose roles are primarily defined in terms of cleaning the employer's home, the nanny's primary responsibility is taking care of the employer's child. Outings to the public park are part of the daily routine for many nannies taking care of children in West Los Angeles. For example, employers often encouraged nannies to go to the park because they wanted their child to spend time outdoors playing with other children. In addition, three employers worked from home and encouraged nannies to leave the household so the employers could be at home alone. When I asked Lucy her favorite thing about being a nanny, she responded, "This - these women, coming to the park." Far from creating social isolation, employment as a nanny provided women the opportunity to regularly attend Pebble Park with others working in similar positions.

Although the casual observer might never notice, the days and times that nannies go to the park are not random. Instead, nannies have regular routines that others at the park know and expect. For example, Alicia, a middle-aged woman with short curly hair, attended the park Monday through Friday with Colby and Nathan (twins, 2 years old). She usually arrived at the park at 10:30 A.M. and left by 12:30 to take the boys to a nearby pre-school. In addition to Alicia, five nannies attended the park Monday-Friday, two attended the park Tuesday-Thursday, and three attended the park Wednesday-Thursday/Friday. Most women arrived between 10:00 and 11:00 A.M. and left the park between 2:00 P.M. and 3:00 P.M.

Nannies frequently voiced their expectations about seeing one another. On a Thursday afternoon, Alicia, told Catalina, a middle-aged Guatemalan nanny, "I'll see you tomorrow" as Catalina prepared to leave the park. Before getting a response, Alicia quickly corrected herself, "Friday. I'll see you Friday." Nannies' expectations about others' park attendance becomes more apparent when women do not arrive when expected. Although going to the park is a routine in these nannies' working lives, this routine is susceptible to change. A nanny's absence from the park can indicate several things - an employer's vacation, a sick child, or in some cases, the loss of employment. One day we learned that Natalia's employer fired her:

"She showed up at work and la señora had a letter waiting for her, a letter of recommendation. She didn't even tell her why," explained Alicia. As other nannies murmured in concern, Alicia continued, "I told my boss what happened and asked her to never do that to me."

Natalia's arbitrary dismissal was the talk of the group for several days. Women dissected the turn of events and speculated about what they might do under similar circumstances. Their conversations reflected their sympathy for Natalia, and their belief that they could easily find themselves in the same predicament.

When a nanny who is a park "regular" fails to show up, women notice and worry about her absence. When Rosa did not come to the park for two consecutive days, several women discussed what might have happened. Although it was clear they were worried Rosa might have lost her job like others before her, no one verbalized this fear, as if saying it out loud might make it true. At the end of the day, when Rosa had not arrived, Joanna instructed Lucy to call Rosa to determine if something was wrong. They learned that Rosa was fine, but Raj (the child she cared for) was sick, and they would return to the park the following week. Lucy exhaled a sigh of relief and relayed the message to several other nannies that waited to hear the news. 
While the literature on domestic work emphasizes the social isolation women experience while working in private homes, working as a nanny also provided women the opportunity to regularly attend Pebble Park. At the park women, escape the constraints of working in the private home and form relationships with other nannies who attend the park at the same time. Consequently, most nannies spent several days a week together, essentially creating "co-worker" relationships.

\section{Sharing care work}

Although nannies enjoy spending time with one another at the park, they would not be there if not for the children in their care. Not only do children provide the warrant for nannies' presence at the park, but it is through helping one another care for children that nannies' bonds with one another are strengthened. Consequently, children also play an important role in the community life at the park. While each nanny is primarily responsible for caring for her own child, nannies watch children collectively. In the following example, Socorro asks Lucy for assistance in taking care of Neil:

Neil plays with a stick and waves it in front of his face. Socorro touches his arm to lower the stick. Annoyed at the interference, Neil continues. "No, Neil, no," Soccoro says. Socorro turns to Lucy and asks her to tell Neil in English to put the stick down. Lucy turns to Neil and tells him to be careful because "you're going to ruin your beautiful blue eyes."

This example demonstrates the ease with which nannies ask for and receive help from one another. Socorro draws on her relationship with Lucy to seek support in caring for Neil. In this case, care work is not solitary, but collective.

Nannies often do each other small favors while working at Pebble Park. These favors can be as simple as watching a child while a nanny takes a bathroom break, or offering snacks or trading toys to appease the children. Nannies are especially careful not to exclude children from any activities. One day, Marlena brought construction paper, stickers, wooden craft sticks and paint for all the children to work on an art project. When Colby and Nathan brought colored clay to the park, Alicia separated the clay into small pieces for other children. Similarly, when Jack rode his bike around the park, Julieta insisted he share the bike with others:

"You have to share, Jack" she tells him in English, as she attempts to distract him with other toys. After he reluctantly gives up the bike, she tells me she often persuades him to leave the bike at home because he doesn't like to share it, and other children always want to ride it. "It's easier to leave it at home," she says.

Sharing is part of the collective ethos at the park, so it is not surprising that Julieta requires Jack to share. Julieta is not only motivated by her desire to teach Jack proper manners, but sharing is important in keeping the peace among both children and nannies. Jack's bike is particularly sought after amongst the children, and Julieta tries to minimize outbursts by forcing Jack to share the bike or trying to avoid bringing it altogether.

Unlike in private homes where nannies are the sole employees and caregivers, at the park nannies turn caring for children into a collective act. Nannies work together by supervising all the children and planning group activities; furthermore, by encouraging children to share toys, nannies attempt to minimize conflict. Working together helps nannies take care of the children and it builds good will amongst the group; collectively caring for children at the park strengthens nannies relationships with one another. 
Sharing food

In the employer's household, food illuminates the boundaries between employers and employees; often domestic workers eat alone rather than eating at a table with their employers (Hondagneu-Sotelo 2001). At the park, it is unusual for nannies to eat alone; in fact, nannies created a weekly ritual around sharing a meal. Thus, in addition to regularly spending time together and sharing care work, nannies also share food with one another, illustrating another dimension of community life at the park.

Every Wednesday, nannies participate in a weekly potluck between 11:30 A.M and 1:00 P.M. The weekly potluck started after a child's birthday party when Maria mentioned they should eat together more often. Alicia suggested a weekly potluck, and the ritual was born. Nannies decided Wednesday was the best day to eat together because it was a day most nannies came to the park. Alicia set up basic guidelines emphasizing optional participation so no one would feel unduly burdened. In the following example, women invite a nanny to join the potluck when they see her sitting by herself:

Alicia, Linda, Julieta, Maria and I sit at the picnic table with plates of food. Socorro is sitting on a nearby park bench watching Neil play with a toy truck. "Come eat!" Linda called to Socorro. Socorro shook her head and mumbled that she was not hungry. "No!" exclaimed Alicia, "Come here and eat with us!" Socorro sheepishly joined us at the table, served herself a plate of food, and began chatting like everyone else.

This example demonstrates how nannies include one another in their activities; they invite Socorro to join the group for lunch even though she has not contributed any items. Sharing food around a table encourages feelings of fellowship and community (Fieldhouse 1986). Inviting Socorro signals that she is part of their group.

Some days, nannies share a feast of homemade tortillas, beans, salsa, and different meats and salads, while other days they order food for delivery. One day, however, only a few people brought food, and the "meal" consisted of crackers, bagels and cream cheese. I commented on the meager selection food to Lucy:

"Do you think the weekly meal is dying?" I ask Lucy. "Dying?"Lucy asks incredulously, "It's not dying. Sit. Eat."

When I suggested to Lucy that perhaps the weekly potluck had run its course, she defiantly told me to sit down and gathered the few nannies who were present that day to eat bagels. Food is both sustentative and symbolic (Lupton 1996). Even without a complete meal, Lucy insisted that we eat together; she seemed to want to prove that the ritual was still relevant.

Potlucks are often festive and lively. Nannies gossip about their boyfriends and husbands, and offer each other advice about relationships or parenting. They also tell jokes and funny stories. One day, when we were sitting at the picnic table, a man approached us:

“Are you all nannies?" a man asked. Marlena replied in English, "Yes, we're the nannies club, we're the Super Nannies Club!' The table erupted in a fit of laughter as the others realized what was said.

Although Marlena's response was meant to be funny, it was also accurate. The community of nannies functions like a club in that it is a recognizable group that meets regularly for a common purpose. Moreover, weekly potlucks expand the image of the lonely nanny who eats in the confines of her employer's home. Through their activities 
together, nannies transform public space into a site for community life. Thus, in addition to routine interactions and shared care work, the weekly potluck also contributes to the sense of community among nannies at Pebble Park.

\section{The boundaries of community}

Nannies are not the only identifiable group at Pebble Park. Other park patrons include lawn bowlers, joggers, golfers, dog walkers, residents of a nearby nursing home, a preschool class at a nearby school, families, and park staff. Most of these patrons never interact with nannies because they use different areas of the park; however, nannies come into regular contact with Latino park staff and their employers. The following section of this paper will compare the ways nannies interact with park regulars, showing how nannies incorporate Latino park staff into their communal life, but exclude their non-Latina female employers.

\section{Park staff}

Like nannies, park employees also work at Pebble Park. The City of Los Angeles Department of Recreation and Parks employs a full and part-time staff of four to six people to maintain the park. The staff includes: Esteban, the 45-year-old senior gardener; Richard, second in command; Danny, a 25-year-old engineering student; and Sebastian, at 23, the youngest employee. Employees at Pebble Park function as gardeners, maintenance workers, and janitors.

Nannies and park employees regularly interact with one another at the park, and the two groups operate in many of the same spaces. However, several incidents in which park patrons complained about nannies' use of the park have occurred during Esteban's tenure as senior gardener. Esteban explained:

"They got mad because some nannies were having a birthday party with their families and another group wanted to use the tables. I told them the tables are first come, first serve. Another time some lady got mad because nannies were using the bathroom. She actually tried to block someone." I ask Esteban if these things still happen at the park and he responds, "Not really. It used to happen a few years ago, but not now. I look out for them (the nannies)."

Although Pebble Park is a public park, a few patrons suggested nannies were not entitled to use its facilities. Just as nannies have subordinate rights to space in the employer's home, their rights to space in public are also contested by community members, often because nannies are of a different race, ethnicity, or economic status than the dominant group (Lan 2006; Parreñas 2001; Yeoh and Huang 1998). As the senior employee, Esteban's maintains order at the park. Esteban is very supportive of the park's Latina patrons and defends their right to space, ensuring that nannies feel comfortable accessing park facilities.

Nannies often go out of their way to greet park staff upon arriving to the park, and they say goodbye when leaving. Like the nannies, Latino park employees perform low-wage labor in a predominantly white neighborhood. Esteban describes the relationship between park staff and nannies in the following way, "They're people we see every day in the park; we're like a family." Although Esteban made the comment metaphorically, for Alicia and Sebastián the description is literal. Alicia is Sebastián's mother. Esteban encouraged Alicia's son to apply at the park when a position became available. 
The familiarity and friendly banter between park staff and nannies creates a light mood at the park and contributes to nannies' sense that the park is their domain. For example, Esteban and nannies frequently joke with one another:

Several nannies and I are walking through the park. Esteban comes out of the park maintenance area and says hello. As he walks towards us, Gaby says loudly, "Hail to the King of the Park, the boss of bosses!" Everyone laughs.

Occasionally park employees join nannies in the weekly potluck. When Richard (a park employee) retired, Esteban scheduled Richard's retirement party on a Wednesday and relied on Alicia to cook the meat for the festivities. In addition, around Father's Day I arrived at the park to a table full of Chinese take-out food. After Alicia instructed me to sit down, Esteban told me they were celebrating Father's Day. Alma chimed in, "We're celebrating Father's Day and the fact that Esteban didn't leave the park." (Alma was making reference to another job offer Esteban had gotten from the city but turned down). On Mother's Day, the gardeners reciprocated and grilled hamburgers and hot dogs for the nannies and the children.

A shared community life at the park is also visible when park employees overlook the minor rule infractions nannies or the children in their care commit. For example, although there are signs posted everywhere that children are not allowed to wade in the stream at the park, the park employees never say a word and often watch in amusement as children frolic in the water. Another day, Esteban cut a large white flower from the park grounds for Rosa after she asked for it. He told her to hide the flower because he did not want everyone thinking they could pull flowers from the flowerbeds.

Nannies also rely on park employees for small favors that ordinary park patrons do not enjoy. For example, when Noah's stroller broke, Catalina enlisted Danny, a young park gardener to repair it. Danny went to the park tool shed, found an appropriate sized screw, and fixed the stroller while simultaneously entertaining Noah by explaining what he was doing. In addition, park employees help nannies by warming food in their kitchen facilities.

The community between park staff and nannies emerges because both groups are composed of Spanish-speaking Latinos that are "outsiders" in the affluent Los Angeles neighborhood in which they work. However, Latino status does not automatically confer membership into community life at the park. For example, nannies and park employees do not interact with Latino gardeners or neighborhood construction workers who patronize an adjacent taco truck. Instead, taco truck patrons stay on the periphery of the park, while nannies and park staff spend their time in the park's interior.

Nannies build camaraderie with Latino park staff in much the same way they do with each other. They see park staff regularly, depend on them for occasional help with the children, and share meals with them during park gatherings. Park employees are not equal members in the nannies' community life-conforming to expected gender norms, their roles are different. For example, when contributing food to weekly potluck, women are much more likely to cook the food, while men grill the meat. Park gardeners help nannies care for children indirectly, by protecting their right to public space or fixing broken items, rather than providing traditional care work. Despite these differences, the groups clearly identify with one another and Esteban describes park staff and nannies as "a family." Thus, nannies' networks at Pebble Park are not only composed of nannies, but are comprised of Latino park employees as well, further complicating the vision of nannies' social isolation. 


\section{Employers}

Despite their best intentions, employers are not invited members of the nannies' community at the park, but their occasional presence contributes to nannies' solidarity with one another. One employer, Lisa, has a particularly bad reputation among the nannies. I was impressed by Lisa's fluent Spanish and took it as a sign she cared about communicating with the women; however, two nannies interpreted her knowledge of Spanish differently:

"She's very nosy," Lucy says. Catalina explains that Lisa calls their employers to gossip about them. Lucy thinks this is a bad influence on her employer, "Now Mandy wants to learn Spanish because she doesn't like it when she can't understand what I'm saying. It's too much; she's my boss, I don't want her to be my friend."

In this example, both Catalina and Lucy express their desire to maintain social distance from employers. Lucy expresses concern about her employer's desire for a closer relationship, saying she does not want to be her employer's friend. Both of the women express concern that Lisa will call their employers to gossip about them. Although Pebble Park is a public space, nannies feel their privacy has been violated when employers arrive at the park unannounced. Most nannies have stories about their employers trying to "catch them" doing something wrong. Although they recognize it is their employers' right and obligation to check on their children, they also perceive the intrusion as a lack of trust.

In addition to the perceived lack of trust, nannies resent employers' presence at the park because it interferes with their jobs. When employers arrive at the park, nannies cannot care for the children in the same way. Several nannies told stories of well-behaved children who became monsters after a 10 minute visit from their parents. "They want attention," one nanny explained. "They become more spoiled and they don't listen to me when their parents are around," added another. In the following example, Raj's dad, Rick visits Raj at the park:

Raj's dad, Rick, approaches us and Rosa (Raj's nanny) quickly stands up and is visibly flustered. She awkwardly introduces Rick and points out Raj's playmates.

Rick tells Raj why he has come to visit saying, "Just like Daddy has an office, this is your office." Raj beams and Rick quickly leaves. Raj burst into tears.

Rick's visit to the park lasted five to 10 minutes. As Rosa struggled to calm Raj after his father's departure, Julieta shook her head in disapproval and voiced a common frustration among the nannies. Raj was happy before Rick arrived at the park but Rick disrupted his routine. Nannies have to work to reclaim their authority, and parents seem to be completely oblivious to the extra work required after their short stints at the park. When nannies are amongst themselves, they turn caring for children into a collective act, and work together to support one another. Women repeatedly treat one another with consideration, and are conscious about how their behavior affects other nannies in their presence. In contrast to the support nannies give to one another, parental intrusions actually create more work for nannies.

The differences between nannies and their employers are also apparent when the groups socialize in close proximity. During a child's birthday party, nannies sat quietly at one table, while employers and family members sat at another. When I asked them to explain the difference between the birthday party and the potlucks they offered the following explanations:

Gaby said, “I don't know. It's uncomfortable. It embarrasses me. I don't want to spend time with the gringas." Rosa chimed in and explained "It's that we have to be reserved around our bosses." "This doesn't feel like a birthday party," Marlena says. "It's that it lacks el sabor Latino," (Latino flavor) says Rosa. 
These comments demonstrate the racial/ethnic boundaries that separate nannies from their employers; nannies invoke feelings of difference based on their employers' non-Latino status. For example, several nannies suggested that the birthday party was less enjoyable because it was not a Latino party. With their employers in attendance, the party lacked "Latino flavor" and nannies felt ill at ease.

According to Hondagneu-Sotelo (2001), domestic workers often characterize the food in their employers' home as bland and unappetizing. During the birthday party, Lucy pointed to the expensive and low-fat bag of organic popcorn with a skeptical look on her face, "You like them?" she asked me. I shrugged and popped one in my mouth as she wrinkled her nose and looked back at her plate of crustless tuna sandwiches and carrot sticks. Throughout the afternoon, nannies shook their heads in dismay and made comments about the "bad" food and the piñata full of cheap plastic toys instead of traditional candy. According to Devault (1991), women use food to project an identity and construct group membership; nannies judged the food at the birthday party as inadequate and lacking. Interestingly, the food at the party was no worse than the most meager potlucks, meals about which no one complained. Thus, nannies' opinions regarding the food's quality had more to do with who provided it, than what it was.

When employers come to the park, nannies feel as if they are "on stage" and scrutinized (Goffman 1959). Nannies enjoy autonomy and relative privacy at Pebble Park. They resent their employer's intrusions because they believe unannounced arrivals actually make caring for children more challenging and are a signal employers do not trust them to do their job. The fact that nannies' experiences with employers at the park are different than their experiences with one reinforces the boundaries between nannies and employers, while simultaneously uniting the nannies around similar grievances.

\section{Discussion}

This paper adds to an existing literature on how "socially isolated" domestic workers "use" public areas to create spaces for community life (Lan 2006; Parreñas 2001). Lan (2006) describes how domestic workers privatize and ethnicize public spheres and exert a collective presence on the urban landscape by "turning train stations into their picnic sites" (p. 161). Similarly, nannies at Pebble Park use the space to create a community of co-workers. Parreñas (2001) shows that Filipina domestic workers in Rome create community by utilizing "hidden pockets" in public spaces where women share their feelings of isolation in the dominant society, and are governed by norms and practices of mutual assistance.

Public spaces are important for domestic workers' community life. As evidenced by Lucy's statement that coming to the park is her favorite part of her job, Pebble Park is important to the women who work there. At Pebble Park nannies come together regularly around similar projects. They turn care work into a collective act by helping watching children together and creating group activities. Working at the park affords nannies opportunities to laugh, gossip, and share stories with one another and reinforces group values like sharing and reciprocity. Through the creation of a weekly potluck, nannies share food and simultaneously convey group membership and identity.

Lan (2006) and Parreñas (2001) suggest that small communities of domestics ultimately extend beyond the public spaces in which they initially began. Similarly, the friendship networks created at Pebble Park ultimately extend beyond the park's boundaries. Nannies lean on each other for social support unrelated to work, and during non-work hours. In addition to planning a Thanksgiving dinner together, when Lucy found out one of the 
nannies' (who no longer attended the park) father died, she started a collection for her and vowed to see her the following evening.

What is surprising about this small community of nannies at Pebble Park is not that it exists - other scholars have documented that nannies create communities in public space. Rather, what is surprising is where and when the community exists for this group of nannies in West Los Angeles. Unlike other studies which characterize domestics' community as "weekend enclaves" which occur during domestics' days off work and in marginal public spaces, my research highlights community building that occurs while women are working in their employers' neighborhood.

The literature on domestic work suggests that housecleaners are the least socially isolated of all domestic workers because they are independent contractors, highly mobile, and create their own work schedules; meanwhile, live-in nannies are the most socially isolated (Romero 1992; Hondagneu-Sotelo 2001). My research complicates previous findings by showing that opportunities for community life are built into domestic service jobs that require caring for children. While some employers try to limit nannies' time away from the home (Hondagneu-Sotelo 2001; Parreñas 2001), nannies whose duties require or allow exiting the employer's household and spending time in the neighborhood have opportunities to expand their social networks in ways that decrease social isolation.

Moreover, nannies are not alone in the creation of a community at Pebble Park. Nannies have friendly relationships with Latino employees at Pebble Park, entitling them to privileges and small favors that other park patrons do not enjoy. Nannies build a community through shared practices and interactions and their perception of their collective difference from employers. These feelings of difference manifest themselves whenever employers come to the park, transforming it from the nannies' space into another site of surveillance. Nannies resent employers' intrusions into their space, particularly because their employers' presence creates additional work for nannies who must calm children down when their parents leave. In particular, domestics want autonomy to perform the tasks and duties associated with their work and prefer that employers leave them to their work (HondagneuSotelo 2001).

Nannies' relationships with one another are cultivated by their frequent interactions, their shared language and culture, and their low-wage positions as service workers in West Los Angeles. Nannies frequently emphasize differences from their employers by pointing out their employers' lack of Latino culture as a deficiency. They express their discomfort and prefer not to spend time with "gringas" at the park. Although employers and nannies share similar interests in that they both care for the children's wellbeing, ultimately their differences in culture and social status result in rigid boundaries around the nannies' community life that employers cannot penetrate. Still, although employers do not form part of the community of park staff and nannies at Pebble Park, their occasional presence is essential to community maintenance. By marking their differences from their employers, nannies reinforce their similarities with one another.

\section{Conclusion}

This research illustrates how opportunities for social networking are built into the structure of nannies' domestic employment. Nannies regularly attended the park with the children in their care, transforming the park into a worksite and the community of nannies into a set of co-workers. However, for domestic workers in Los Angeles, the group of nannies at Pebble Park was particularly privileged. They worked in an affluent neighborhood, earned 
relatively high wages for their work, and a few even received benefits like paid vacations and holidays. Most were live-out workers with their own vehicles, and all had the freedom to leave their employer's household during the workday. Even with these advantages, they could not escape domestic work's constraints, such as its instability. Children in this neighborhood start pre-school by age three, limiting nannies' duration of employment. Two years later, all the nannies that spent so much time together at Pebble Park have been replaced by an entirely new group of nannies taking care of different children. The "super nannies club," or at least the one that existed for a year at Pebble Park, no longer exists for the group of women described in this article.

Thus, implications of these findings for organizing household workers are mixed. As long as immigrant women move in and out of the domestic service occupation, in and out of neighborhoods, and in and out of each others' lives, organizing them will continue to be especially challenging. On the other hand, advocacy organizations have made inroads with respect to organizing domestic workers. This research shows that domestic workers have a collective identity derived from their work, social networks composed of other domestics, and a common work site. All are important prerequisites for organizing. Challenging the notion that all domestic workers are socially isolated, this research invites scholars to expand their views on immigrant communities and where they are located.

Acknowledgements I am grateful to the nannies and park staff who graciously allowed me to become part of their social circle. Grateful acknowledgements are also owed to Roger Waldinger, Vilma Ortiz, Jooyoung Lee, Javier Auyero and two anonymous reviewers at Qualitative Sociology, for their insightful comments on earlier drafts of this paper. This research was supported by the UC Labor \& Employment Research Fund and the ASA Minority Fellowship Program.

Open Access This article is distributed under the terms of the Creative Commons Attribution Noncommercial License which permits any noncommercial use, distribution, and reproduction in any medium, provided the original author(s) and source are credited.

\section{References}

Clark-Lewis, E. (1994). Living in, living out: African American domestics and the great migration. Washington D.C.: Smithsonian Institution.

Cohen, R. (1991). Women of color in white households: Coping strategies of live-in domestic workers. Qualitative Sociology, 14, 197-215.

Cranford, C. J. (2005). Networks of exploitation: Immigrant labor and the restructuring of the Los Angeles janitorial industry. Social Problems, 52, 379-397.

DeVault, M. (1991). Feeding the family: The social organization of caring and gendered work. Chicago: University of Chicago Press.

Dill, B. T. (1988). 'Making your job good yourself': Domestic service and the construction of personal dignity. In A. Bookman \& S. Morgen (Eds.), Women and the politics of empowerment, pp. 33-52. Philadelphia: Temple University Press.

Dudden, F. (1983). Serving women: Household service in nineteenth-century America. Middletown: Wesleyan University Press.

Emerson, R. M., Fretz, R. I., \& Shaw, L. L. (1995). Writing ethnographic fieldnotes. Chicago: University of Chicago Press.

Fantasia, R. (1988). Cultures of solidarity. Berkeley, CA: University of California Press.

Fieldhouse, P. (1986). Food and nutrition: Customs and culture. Kent: Croom Helm.

Glenn, E. N. (1986). Issei, nisei, warbride. Philadelphia: Temple University Press.

Goffee, R. (1981). Incorporation and conflict: A case study of subcontracting in the coalindustry. Sociological Review, 29, 475-97.

Goffman, E. (1959). The presentation of self in everyday life. New York: Doubleday Anchor. 
Hagan, J. (1998). Social networks, gender, and immigrant incorporation: Resources and constraints. American Sociological Review, 63, 55-67.

Hodson, R., Welsh, S., Rieble, S., Sorenson Jamison, C., \& Creighton, S. (1993). Is worker solidarity undermined by autonomy and participation? Patterns from the ethnographic literature. American Sociological Review, 58, 398-416.

Hondagneu-Sotelo, P. (1994a). Regulating the unregulated: Domestic workers' social networks. Social Problems, 41, 201-215.

Hondagneu-Sotelo, P. (1994b). Gendered transitions: Mexican experiences of immigration. Berkeley: University of California Press.

Hondagneu-Sotelo, P. (2001). Doméstica: Immigrant workers cleaning and caring in the shadows of affluence. Berkeley: University of California Press.

Katz, J. (2001). Analytic Induction. In N. J. Smelser \& P. B. Baltes (Eds.), International encyclopedia of the social and behavioral sciences, pp. 480-484. Oxford, UK: Elsevier.

Katzman, D. (1978). Seven days a week: Women and domestic service in industrializing America. New York: Oxford University Press.

Lan, P. (2003). Negotiating social boundaries and private zones: The micropolitics of employing migrant domestic workers. Social Problems, 50, 252-549.

Lan, P. C. (2006). Global cinderellas: Migrant domestics and newly rich employers in Taiwan. Durham: Duke University Press.

Littler, C. R., \& Salaman, G. (1984). Class at work: The design, allocation, and control of jobs. London: Batsford.

Lupton, D. (1996). Food, the body and the self. London: Sage.

Macdonald, C. (1998). Manufacturing motherhood: The shadow work of nannies and au pairs. Qualitative Sociology, 21, 25-53.

Palmer, P. (1989). Domesticity and dirt: Housewives and domestic servants in the United States: 1920-1945. Philadelphia: Temple University Press.

Parreñas, R. (2001). Servants of globalization: Women, migration, and domestic work. Stanford: Stanford University Press.

Rollins, J. (1985). Between women: Domestics and their employers. Philadelphia: Temple University Press.

Romero, M. (1988). Chicanas modernize domestic service. Qualitative Sociology, 11, 319-34.

Romero, M. (1992). Maid in the U.S.A. New York: Routledge.

U. S. Census Bureau. (2000). Census of population and housing. Washington, D.C.: Government Printing Office.

Wrigley, J. (1995). Other people's children. New York: Basic Books.

Yeoh, B., \& Huang, S. (1998). Negotiating public space: Strategies and styles of migrant female domestic workers in Singapore. Urban Studies, 35, 583-602.

Amada Armenta is a Ph.D. candidate in the Department of Sociology at the University of California, Los Angeles. Her current research examines the local enforcement and implementation of national immigration policies. 